\title{
APORTES FREIREANOS PARA A FORMAÇÃO CONTINUADA DE PROFESSORES: RELATO DE UMA EXPERIÊNCIA
}

\author{
Iône Inês Pinsson Slongo ${ }^{1}$ \\ Elison Antonio Paim ${ }^{2}$ \\ Monalisa Paulino ${ }^{3}$
}

\begin{abstract}
Resumo
O estudo decorre do projeto "O Pensamento de Paulo Freire na Educação Brasileira: análise de Sistemas Públicos de Ensino a partir da década de 1990”, coordenado pela Cátedra Paulo Freire (PUC/SP), com ramificações em diversos estados brasileiros. O recorte aqui apresentado focou de modo particular a formação continuada de professores, concebida e desenvolvida durante o movimento de reorientação curricular ocorrido no município de Chapecó (SC), no período de 1997 a 2004. Os dados foram produzidos mediante entrevista semiestruturada, realizada com oito docentes envolvidos na implementação dessa política educacional. Através da análise de conteúdo foi possível identificar: as condições objetivas que oportunizaram a implementação da proposta, as principais ações voltadas à formação continuada dos professores, os avanços promovidos e dificuldades enfrentadas pela política educacional, na visão dos docentes.
\end{abstract}

Palavras-chave: Movimento de Reorientação Curricular; Formação Continuada de Professores; Reflexão sobre a Prática Pedagógica; Paulo Freire

\section{FREIRIAN SUPPORTS TO THE CONTINUED FORMATION OF TEACHERS, REPORT OF AN EXPERIENCE}

\footnotetext{
Abstract

${ }^{1}$ Iône Inês Pinsson Slongo. Doutora em Educação pela UFSC. Docente permanente do Programa de Pósgraduação em Educação da Universidade Federal da Fronteira Sul (PPGE/UFFS) - Campus Chapecó. Av. Fernando Machado, 108 E - CEP 89802-112. Endereço eletrônico: ione.slongo@uffs.edu.br.

22 Elison Antonio Paim. Doutor em Educação pela UNICAMP. Professor Adjunto da Universidade Federal de Santa Catarina (UFSC). Professor permanente do Programa de Pós-Graduação em Educação (PPGE) e do Mestrado profissional em Ensino de História (Profhistória/UFSC). Rua Maestro Aldo Krieger, 166, apt. 101, Córrego Grande, Florianópolis - SC - CEP 88037-500. Endereço eletrônico: elison.paim@ufsc.br

${ }^{3}$ Monalisa Paulino. Mestranda do Programa de Pós-Graduação em Educação da Universidade Federal da Fronteira Sul (PPGE/UFFS) - Campus Chapecó. Av. Fernando Machado, 108 E - CEP 89802-112. Endereço eletrônico: monalisaxx2010@ hotmal.com
} 
The study composes the project "Paulo Freire's thought in Brazilian Education: analysis of public education systems from the decade of 1990", coordinated by the Chair Paulo Freire (PUC/SP), with ramifications in several brazilian states. The presented clipping focused, in a particular way, the continued formation of teachers conceived and developed during the movement of curriculum reconstruction occurred in the city of Chapecó (SC) in the period from 1997 to 2004. The data were produced through semi-structured interview. Through the analysis of content it was possible to identify: the objective conditions that gave the opportunity to the implementation of the proposal, the main actions devoted to the continued formation of teachers, the proportioned advances and the difficulties faced by the educational policy, in the docents vision.

Keywords: Movement of Curriculum Reorientation; Continued Formation of Teachers; Reflection About the Pedagogical Practice; Paulo Freire

\title{
APORTACIONES FREIRIANAS PARA LA FORMACIÓN CONTINUADA DE DOCENTES: RELATO DE UNA EXPERIENCIA
}

\begin{abstract}
Resumen
El estudio constituye el proyecto "El Pensamiento de Paulo Freire en la Educación brasileña: Análisis de Sistemas Educativos Públicos de la década de 1990”, coordinado por la Cátedra Paulo Freire (PUC / SP), con ramificaciones en diversos estados brasileños. El recorte presentado se ha centrado, en particular, en la formación continua de los docentes diseñados y desarrollados durante el movimiento de reorientación curricular que ocurrió en Chapecó (SC) de 1997 a 2004. Los datos han sido producidos por medio de entrevistas semiestructuradas. A través del análisis de contenido se identificaron: las condiciones objetivas que han permitido la aplicación de la propuesta, las principales acciones volcadas para la formación continua de los docentes, los avances promovidos y las dificultades que enfrenta la política educativa, en opinión de los docentes.
\end{abstract}

Palabras clave: Movimiento de Reorientación Curricular; La Formación Continua de Los Docentes; La Reflexión sobre La Práctica Docente; Paulo Freire 


\section{INTRODUÇÃO E CONTEXTUALIZAÇÃO TEÓRICA}

A formação continuada de professores no Brasil possui uma trajetória marcada por diferentes tendências. Em oposição à perspectiva de formação continuada pautada no processo de atualização dos docentes, mediante aquisição de novos conhecimentos, os quais circulam de quem sabe para quem pouco sabe, vêm ganhando destaque as correntes de orientação crítico-reflexiva-transformadora (FREIRE, 2001; ALARCÃO, 2003; CONTRERAS, 2002; IMBERNÓN, 2009). Estas, de diferentes maneiras, pautam a formação continuada de professores na possibilidade de (re)construção teórico-conceitual, a partir da reflexão crítica dos sujeitos sobre suas próprias práticas pedagógicas. Portanto, o lócus principal desta formação é a própria escola.

Tais abordagens defendem a formação continuada de professores rompendo com modelos verticalizados e antidialógicos, de existência esporádica e descontextualizada, pautando-a em processos formativos que ocorrem ao longo da vida, numa forte articulação entre o pensar e o agir. Essa perspectiva vem influenciando significativamente os programas de formação continuada de professores no país (BRZEZINSKI; GARRIDO, 2001), contribuindo para a recriação de políticas e de práticas educativas.

Para Freire $(2001,1997)$, pensar a formação continuada de professores implica pensar as finalidades da educação e a possibilidade de contribuir para a consecução de um projeto maior, qual seja a construção de uma sociedade mais humana e justa, pela via da participação, da reflexão crítica e da ação transformadora. Desse modo, a ideia de formação continuada decorre do conceito de inacabamento, de inconclusão, que gera um movimento constante no sentido do ser mais. O autor descreve a formação docente como um processo contínuo de desenvolvimento profissional, que vai além da formação inicial e se funda no exercício crítico-reflexivo da docência.

Freire foi um dos pioneiros a instituir a reflexão como elemento estruturante da formação continuada dos educadores. Anunciou que o espaço privilegiado para essa formação é a escola e o seu conteúdo, o processo educacional ali desenvolvido, de tal forma que o professor se tornará um investigador do seu próprio fazer educacional. Contudo, a reflexão sobre a própria prática pedagógica, além de permanente, necessita ser crítica, ancorada em uma análise mais ampla, em diálogo com o contexto sócio-político-econômico-cultural, pois, “[...] nenhuma prática educativa se dá no ar, mas num contexto concreto, histórico, social, cultural, econômico, político, não necessariamente idêntico a outro contexto" (FREIRE, 1987, 
p. 17).

Assim, o cotidiano do professor passa a ser o ponto de partida e a finalidade da formação continuada. Situar a formação docente na realidade profissional, toma o educador como sujeito ativo, questionador, crítico, reflexivo e propositivo, portador e construtor de novos conhecimentos sobre a docência.

Portanto, uma ação docente que já não se limita à execução de "tarefas" pensadas por outros, mas que se engaja em um projeto educacional mais amplo, protagonizando-o, percebendo a realidade e refletindo criticamente sobre ela, contribuindo para promover os conhecimentos necessários às mudanças prioritárias. Trata-se de uma prática docente horizontalizada, que, ao democratizar as decisões na relação pedagógica, torna a escola um fecundo campo de formação profissional, porque valoriza o conhecimento em ação e toma o professor sujeito, capaz de refletir e teorizar sobre ela. O papel do professor passa a ser então o de refletir, investigar e gerar conhecimento na ação, motivado pelas problemáticas vivenciadas na sala de aula.

Para Freire (2001), as ações transformadoras são precedidas por uma leitura crítica do mundo, que inclui a possibilidade de mudança e que só é possível mediante a curiosidade epistemológica, que desperta a imaginação e a criatividade.

Por sua vez, o compartilhamento do mundo lido, necessita da dialogicidade, outra categoria fundante do pensamento freireano. Particularmente com relação à formação continuada de professores, o autor argumenta em favor da transformação dialógica da realidade vivida, em que “[...] o espaço pedagógico é um texto para ser constantemente 'lido', interpretado, 'escrito' e 'reescrito" (FREIRE, 2001, p. 109). Trata-se, pois, de inserir os professores neste movimento de reflexão na ação, de modo a construir a consciência crítica a respeito do seu próprio fazer pedagógico e a convicção na possibilidade de transformação (SILVA, 2004).

No período de 1997 a 2004, a rede pública de ensino do município de Chapecó (SC) vivenciou um movimento de reorientação curricular pautado em pressupostos contidos na concepção de educação de Paulo Freire (FREIRE, 1997; 1999; 2001 e 2006). A investigação temática proposta por Freire (2008) orientou o processo, pautando-o no trabalho interdisciplinar, via temas geradores. O projeto envolveu diferentes níveis e modalidades de ensino e todas as áreas do conhecimento. Um arrojado programa de formação continuada de professores foi concebido e implementado, tendo como elemento central a reflexão crítica dos docentes sobre a própria prática pedagógica, notadamente a partir dos problemas vivenciados no cotidiano escolar, de modo a explicitar e analisar criticamente as concepções teóricas 
implícitas, os valores, atitudes e procedimentos, muitas vezes, mobilizados de forma inconsciente, numa espécie de auto avaliação e reflexão constante sobre a própria prática pedagógica (STUANI, 2010).

O estudo ora apresentado assumiu o desafio de melhor compreender o modo como a formação continuada de professores foi concebida e desenvolvida. De modo mais específico, teve o objetivo de apreender e analisar as principais práticas formativas implementadas e suas implicações no cotidiano da sala de aula, bem como, os avanços e as dificuldades experimentadas. A expectativa é de que os dados gerados possam contribuir para a recriação de políticas e de práticas educativas, numa perspectiva crítico-emancipadora.

\section{SOBRE A PESQUISA}

A abordagem qualitativa de investigação (MINAYO, 2003) foi adotada neste estudo, que focou a política de formação continuada de professores em vigor durante o movimento de reorientação curricular ocorrido na rede pública municipal de Chapecó (SC) no período de 1997 a 2004. Esse movimento envolveu as diferentes modalidades de ensino e todas as áreas do conhecimento, como também, um contingente de 1500 professores vinculados a 63 escolas, nos segmentos de Educação Infantil, Ensino Fundamental (anos iniciais e finais) e Educação de Jovens e Adultos. O movimento pautou-se numa educação popular crítica, de orientação freireana (STUANI, 2010).

Os dados foram coletados em 2012/2013, mediante entrevistas semiestruturadas (BOGDAN; BIKLEN, 1994), que possibilita questões de exploração e descrição pormenorizada e assim, a recuperação, de forma retrospectiva, de acontecimentos que marcaram significativamente o processo educacional em estudo. As entrevistas foram gravadas e transcritas.

A amostra foi composta por 8 professores que participaram efetivamente do movimento de reorientação curricular, ao longo dos oito anos. Houve o cuidado de compor uma amostragem diversificada, com docentes dos distintos segmentos (Educação infantil, Anos iniciais, Anos finais e EJA) e que desempenharam diferentes funções no processo (direção, coordenação e docência). Também foi necessário considerar a disponibilidade dos sujeitos para participar do estudo. Tais critérios possibilitaram a seguinte composição: 2 Diretores de Departamentos (Educação Infantil e Educação de Jovens e Adultos), 4 Coordenadores de área (Ciências, Matemática, Língua Portuguesa e Educação Infantil), 2 professores (Educação Infantil e Anos Iniciais). Na ocasião das entrevistas todos os docentes informaram 
possuir formação em nível de pós-graduação, sendo 6 em programas lato sensu e 2 stricto sensu na área da Educação.

Para o tratamento dos dados utilizou-se a metodologia de análise de conteúdo (BARDIN, 2009), realizada em três etapas: (1) pré-análise: identificação e sistematização das informações através de leitura flutuante do corpus das entrevistas; (2) seleção das unidades de análise: identificadas pelo frequenciamento e relevância implícita e, (3) categorização: contendo as unidades de análise e compondo o conjunto de significados que atendem aos objetivos do estudo.

\section{A SINTONIA NECESSÁRIA NA COMPOSIÇÃO DE UM GRUPO DE TRABALHO}

Em 1997, mediante a decisão de que a política educacional na rede pública municipal de Chapecó se pautaria nos princípios da educação popular (cidadania, democracia, autonomia e trabalho coletivo), uma das primeiras ações da secretaria municipal de educação foi definir um grupo que desencadearia e coordenaria o processo de construção e implementação dessa proposta educacional. Os docentes desafiados a assumir esta atribuição possuíam algumas afinidades:

Eu tinha uma aproximação com os movimentos sociais [...]. Simpatizava com essa ideia de luta, de visualizar o outro, comecei a perceber o quanto a gente pode fazer a diferença independente do espaço que a gente está. (P1, 2012, grifos nossos).

Eu tinha uma experiência com os movimentos sociais de educação popular nas comunidades eclesiais de base e fiz especialização em educação popular [...]. Eu fui convidada a compor a equipe $e$ organizar um programa de EJA pela minha trajetória política e de militância. (P4, 2012, grifos nossos).

Eu sempre fui muito militante [...], sempre fui pra rua, e sempre fiz questão de fazer algumas opções [...]. Nesse processo, quando você organiza as diferentes secretarias, você precisa de pessoas que tenham um pouco essa concepção mais de esquerda [...], para organizar uma escola ou um espaço de educação [...] para inserção da população [...], a questão foi de concepção mesmo [...]. (P5, 2012, grifos nossos).

Observa-se o compartilhamento de concepções e experiências calcadas na compreensão de que os problemas sociais são criações humanas, possíveis de serem transformados. A 
opção pela educação emancipatória, precursora do pensar crítico para o desvelamento e a transformação da realidade, orientou a política educacional:

Elaboramos os documentos, sempre tendo presente: que escola a gente tem, que escola a gente quer: que currículo a gente tem, que currículo a gente quer: que avaliação a gente tem que avaliação a gente quer; como são os horários e a estrutura escolar, como é que a gente tem como é que a gente quer. Nós tinha uma intencionalidade, um projeto a ser construído, tinha compromisso com uma educação emancipadora e libertadora [...]. (P4, 2012, grifos nossos).

Elaboramos uma proposta prévia, onde a gente discutia currículo, metodologia de ensino, estrutura escolar, carga horária das unidades curriculares e processo de avaliação [...]. O que a gente queria era uma escola que respeitasse o processo do aluno, mas que colocasse ele em movimento, que partisse da necessidade do aluno, uma avaliação que não fosse pra amedrontar. (P5, 2012, grifos nossos).

O que facilitava é que nós tínhamos muita certeza do que nós queríamos, nós tínhamos um cunho político, pedagógico, [...], acreditávamos na transformação como acredito ainda hoje, que a educação faz parte e ajuda na transformação. (P3, 2012, grifos nossos).

Os aspectos priorizados mostram que a proposta educacional amparou-se na compreensão de que a educação é uma forma de intervenção no mundo (FREIRE, 2001), um ato essencialmente político, afinal, "Não posso ser professor se não perceber cada vez melhor que, por não poder ser neutra, minha prática exige uma definição. Uma tomada de posição. Decisão. Ruptura. Exige de mim que escolha entre isto e aquilo" (FREIRE, 2001, p. 115).

O projeto educacional foi sendo fortalecido e qualificado com a participação da equipe docente e da comunidade escolar. Nesse sentido, os dados mostram que algumas condições objetivas imprescindíveis ao projeto:

A gente conseguiu garantir que $20 \%$ da carga horária dos professores para planejamento e estudo. E como é que você garante isso, se não pode liberar o aluno? Tendo um professor a mais. Lembro que a cada 5 ou 6 turmas tinha que ter um professor a mais, porque ele tinha que ser o coringa para fechar aquele horário de aula. (P4, 2012, - grifos nossos).

Tínhamos um horário por semana que era de meio turno além dos horários de planejamento. Então, era mais ou menos assim: para 
40 horas semanais, eram 32 em sala, seis de planejamento e duas de orientação pedagógica. Nunca no espaço escolar tivemos tanto tempo para o planejamento. (P7, 2013, grifos nossos).

Além da disponibilidade de tempo para os professores se dedicarem ao estudo da proposta e planejamento das ações, a secretaria garantiu assessoria permanente à equipe pedagógica:

Em 1998 a gente traz uma assessoria [...], e aí desencadeou esse movimento de reorientação curricular, com pesquisa, a partir da pesquisa, análise das falas, identificar os limites explicativos nas falas, os temas geradores, o contra tema que é a visão do educador, organizar a rede temática, o que é a rede temática, 0 momento que você organiza a programação do conteúdo, [...] o momento da interdisciplinaridade, [...] a rede temática e concluía com a organização dos três momentos [...] que é estudo da realidade, a organização do conhecimento e a aplicação do conhecimento. Desencadeamos esse movimento em toda a secretaria municipal da educação. (P4, 2012, grifos nossos).

Recordo que nós tínhamos pessoal que vinha de fora o tempo todo. As orientações aconteceram sempre, ininterruptamente, eu diria que em tempo integral, durante todo o processo. A secretaria fazia esse trabalho junto às escolas, vinha ver os pontos onde tínhamos dificuldades, tínhamos orientadores dentro da escola. (P7, 2013, grifos nossos).

Em paralelo a essas condições de trabalho, outras demandas, em especial em termos de formação, foram se mostrando prioritárias. Coube à equipe pedagógica mediar tanto a ação pedagógica como a reflexão e problematização decorrentes, propondo alternativas de superação.

\section{O MOVIMENTO DE REORIENTAÇÃo CURRICULAR E A FORMAÇÃo CONTINUADA: O DUPLO DESAFIO}

A formação continuada de professores durante o movimento de reorientação curricular foi concebida com o objetivo de promover uma atitude ativa dos docentes diante dos desafios enfrentados no processo pedagógico. Opunham-se à proposta em implantação o enraizamento de um ensino orientado por um currículo fragmentado e o alto índice de evasão. Nesse contexto, tirar os professores da condição passiva, levando-os a uma inserção crítica e a uma 
prática transformadora, foi o desafio que norteou o projeto de formação continuada no movimento de reorientação curricular.

O ponto de partida foram as dificuldades vivenciadas pelos docentes no processo de implantação da nova política educacional. Assim, a secretaria de educação organizou o processo formativo em duas frentes: uma, com a própria equipe pedagógica da secretaria e a outra, com os docentes, direções das unidades escolares e demais membros da comunidade escolar.

Essa decisão pautou-se na compreensão de que a formação seria desenvolvida a partir da análise crítica e reflexão dos docentes sobre a proposta em ação, problematizando-a, identificando inconsistências e buscando elementos para sua superação. Ou seja, os professores foram conhecendo e entendendo melhor a proposta no seu processo de implementação:

Então, chega a nova proposta e aí não tem como você preparar o professor primeiro, não houve adaptação, estruturação, 0 processo foi acontecendo [...]. A formação do professor foi acontecendo na medida em que a proposta foi sendo implantada. Ninguém dominava a mudança ou tinha segurança nela, nem mesmo os coordenadores. Vinham pessoas de fora para realizar palestras e depois iam embora [...]. Ouvir sobre a proposta, de quem entendia do assunto, era muito lindo, mas colocá-la em prática foi muito desafiador. (P7, 2013, grifos nossos).

[...] foi uma aprendizagem no contexto. A nossa formação se deu junto com a rede municipal, [...] foi se dando dentro dessa proposta, nesse momento, ela foi uma troca, na verdade. Então eu não era uma pessoa que estava pronta, formada pra trabalhar [...] porque a maioria do grupo lá tinha sim seus contextos, sua formação mas não com profundidade. (P3, 2012, grifos nossos).

Observa-se que não só a formação dos professores ocorreu no processo, mas, também, a da equipe pedagógica. Como é possível vislumbrar, a formação aconteceu de forma intensa, no espaço escolar, e o conteúdo dessa formação brotou da própria prática pedagógica, em sintonia com os pressupostos de uma educação popular, pautada na abordagem temática:

Toda nossa formação era voltada em sustentar esse trabalho da pesquisa do tema gerador, da rede temática, dos três momentos. Então a gente buscava assessorias, leituras, subsídios 
que fossem fortalecendo e consolidando na escola. Então a gente tinha o fórum de dirigentes, a formação pedagógica e política, o fórum dos coordenadores pedagógicos, a formação pedagógica $e$ política, tinha nossas diretoras que tinham que fazer a formação das nossas equipes, tinha a nossa formação uma vez por mês [...] as intervenções nas escolas uma vez por semana, [...] era muito trabalho [...]. (P4, 2012, grifos nossos).

A gente investiu muito na formação continuada lá no espaço mesmo; a gente tava sempre nas escolas, sempre nos centros de educação infantil; os grupos chamavam, alguns queriam a gente lá pra cada vez que eles parassem pra planejar a gente estivesse junto, pensando [...]. Acho que a formação foi muito interessante, foi uma coisa em que a gente investiu, a gente não descansava, o nosso lugar não era na Secretaria da Educação, nosso lugar eram os grupos, nas escolas [...]. (P5, 2012, grifos nossos).

O ponto de partida foi a problematização das concepções dos próprios educadores e as demandas e necessidades evidenciadas na prática pedagógica, via tema gerador. Partir da realidade foi a estratégia não apenas para o trabalho pedagógico com o estudante, mas também para a formação continuada dos educadores. A perspectiva de colaboração e coformação permeou o trabalho:

A secretaria selecionava, a partir das dificuldades, os temas a serem debatidos. Então não era só a secretaria que definia o que a gente ia estudar ou fazer, era também os professores e os diretores eleitos que ajudava a contribuir e solicitar diferentes pautas pra que a gente pudesse dar conta das dificuldades. A formação ocorreu em todos os momentos, inclusive enquanto secretaria a gente também definia os dias de estudo. (P1, 2012, grifos nossos).

Ímos para as escolas trabalhar com os professores sempre numa perspectiva de envolver os professores a partir daquilo que era problema/dificuldade pra eles. Então discutir a formação a partir daquilo que era problema no seu fazer pedagógico, olhando então para o mirante da educação popular $e$ para o processo de investigação temática. (P2, 2013, grifos nossos).

Mas a equipe pedagógica também estava atenta a outras demandas do processo formativo: 
Algumas demandas vinham das escolas e outras a gente via que tinha que avançar, então, a gente também colocava para as escolas pontos para avançar no processo, uma vez que o objetivo maior era que, na medida que o processo fosse avançando, as escolas ganhassem uma certa autonomia, uma certa emancipação, de poderem propor também alternativas, não só esperar que a gente propusesse [...], mas que eles também se sentissem sujeitos [...]. $(P 1,2012)$.

Evidencia-se um esforço no sentido de levar o grupo a tomar distância da realidade vivida e das próprias concepções e práticas, um processo de ação-reflexão, com vistas à tomada de consciência para as mudanças necessárias. O movimento buscou potencializar a compreensão dos docentes em relação à proposta. Nesse sentido, a opção foi pela realização de debates, leituras e seções coletivas de estudo:

A opção pela educação popular na rede municipal criou a necessidade de fazer outros estudos, fazer outras reflexões, beber em outras fontes e a gente começou a fazer isso, porque se a gente vai fazer a pesquisa para depois definir o currículo, os conteúdos a serem trabalhados, então, precisamos estudar como se faz pesquisa, quais os autores que a gente tem, que contribuem para compreender qual a postura, qual o papel do entrevistador [...]. (P4, 2012, grifos nossos).

Naquele período a gente estudava mesmo, [...] sentava em grupo, lia os textos, discutia em que aquilo poderia ajudar a gente em sala. No começo foi introduzido o tema gerador, as redes temáticas, essa questão toda que para todos nós foi muito desafiadora. A gente precisava ler, estudar, buscar subsídio pra poder dar conta daquilo. A gente ia pras escolas ou mesmo na formação naqueles dias da parada, [...] a gente tinha que intervir e a gente estudava muito antes de fazer essa intervenção, antes de ir pra escola. (P1, 2012, grifos nossos).

Toda nossa formação era voltada em sustentar esse trabalho da pesquisa do tema gerador, da rede temática, dos três momentos, então a gente buscava assessorias, leituras, subsídios que fossem fortalecendo e consolidando isso na escola. (P4, 2012, grifos nossos).

A formação, tanto da equipe coordenadora, quanto dos docentes, foi imprescindível para a consecução da proposta e pautou-se na estruturação das grandes linhas de trabalho, uma espécie de lastro, que orientou o trabalho pedagógico nas unidades escolares. Nesse 
processo, ganhou destaque o trabalho coletivo, um dos princípios da política educacional implementada:

\begin{abstract}
A gente tinha representantes das escolas, trabalhava em conjunto, distribuía as atividades, um grupo pegou a avaliação, um grupo pegou a estrutura, tínhamos diretores, especialistas na época, supervisores, orientadores, e a gente tinha professores e também alunos do ensino regular que nos auxiliavam. (P4, 2012, grifos nossos).

Inicialmente foi organizando o projeto político pedagógico, que tinha o marco situacional, o marco referencial e dentro desses marcos foram definidos os princípios que organizariam a educação nesse processo, [...] que eram: trabalho coletivo, cidadania, democracia e autonomia. Procurando dialogar com esses princípios, qual seria a posição metodológica para a sala de aula que poderia fazer esses princípios se tornar prática? Foi assim que se chegou então ao tema gerador. (P2, 2013, grifos nossos).

$A$ formação era coletiva $e$ os problemas eram socializados para discutir coletivamente. Então, na formação, os professores tinham afinidade de discutir aquele assunto, tanto com nós da secretaria da educação como dentro do espaço do CEIM ${ }^{4}$, também com coordenadores. [...] havia sempre momentos diferenciados, momentos específicos com professor e coordenação da secretaria, momentos do professor com os próprios colegas, com a coordenadora do CEIM. Então, sempre havia esse movimento, momentos que você não estava sozinho, se tinha dificuldades, tu tinha com quem discutir. [...] havia um rodízio em todos os CEIMs da rede. (P3, 2012, grifos nossos).
\end{abstract}

Observa-se que a formação de professores no contexto de uma política educacional que prima pela construção do currículo, necessita pautar-se no diálogo permanente entre os diferentes saberes. Desse modo, as ações formativas apoiaram-se fortemente no trabalho coletivo e interdisciplinar.

\title{
4 PONTOS POSITIVOS A DESTACAR
}

Observou-se que a formação proporcionada, na medida em que promoveu uma melhor compreensão dos docentes sobre a proposta educacional e pedagógica em ação, gerou resultados positivos, notadamente a inserção de um maior número de educadores no movimento, com participação efetiva no processo. Como consequência, foi possível observar

\footnotetext{
${ }^{4}$ Centro de Educação Infantil Municipal.
} 
a gradativa conquista de autonomia no fazer pedagógico sem, contudo, perder-se de vista a importância do trabalho coletivo, interdisciplinar:

Nessa formação nós conseguimos grupos que se propuseram a ir para os seminários [...] relatar as experiências do seu tema gerador [...]. Então a gente conseguiu fazer seminários fantásticos, trazendo a educação infantil como pauta também pra essas coisas, a partir da realidade, daquilo que as pessoas faziam [...]. A gente tinha essa preocupação, as pessoas têm que contar para alguém o que estão fazendo [...]. E eles se esmeravam pra fazer essas exposições, e a ideia era fazer a partir daquilo que a gente tá discutindo [...]. E quando você relata passa a acreditar naquilo que tu faz aquilo te empodera, [...] a pessoa estava tentando construir uma prática e se sentindo sujeito daquilo [...]. (P5, 2012, grifos nossos).

Eles mesmos pensavam as oficinas para solucionar os problemas de aprendizagem, eles pensavam instrumentos de avaliação, propunham outras dinâmicas para a escola, para superar certas dificuldades, eles mesmos se propunham a organizar a pauta do momento de estudo coletivo e tocavam, se propunham em organizar eles próprios a rede temática, sem interferência da gente, escolher o tema gerador, sem a necessidade da presença da secretaria. (P1, 2012, grifos nossos).

Nos últimos quatro anos já estávamos mais embasados, já estávamos fazendo a coisa acontecer de outra forma. Tínhamos o suporte de alguém da secretaria que vinha ver os pontos onde estavam às dificuldades, muitas vezes, sentavam com cada professor em particular, mas, geralmente era coletivo. (P7, 2013, grifos nossos).

Muita gente se identificou com a proposta, no sentido de que a proposta dava possibilidade dos professores serem sujeitos, criarem, pensarem, refletirem sobre sua prática e eles falavam muito da importância do trabalho coletivo, da troca entre colegas. (P2, 2013, grifos nossos).

Que saudade do tempo que a gente relatava experiências, preparava aulas, porque a gente preparava aulas, por exemplo, sobre vozes verbais, é conteúdo que a oitava série tem que dominar, agora a fala é essa, o tema gerador é esse, como é que eu faço pra desenvolver essa aula e aí se prepara uma aula sobre isso, o outro sobre aquilo, depois socializava. (P8, 2013, grifos nossos).

Essa reflexão na ação está em sintonia com a proposição de Freire (2001), quando argumenta que a prática ensina, contudo, esse conhecimento não é suficiente: é necessário 
conhecer melhor o que já conhecemos e conhecer o que ainda não conhecemos. Refere-se também, que o mundo não é, está sendo, e que estar no mundo não se reduz a ler a realidade, mas requer, a partir dessa leitura, desafiar-se a modificar tal realidade.

\section{OS ENTRAVES APONTADOS}

Alguns depoimentos explicitam as principais dificuldades vivenciadas na implementação da proposta. Entre eles, recebeu destaque a questão da resistência dos professores à mudança:

$O$ povo dizia por que trabalhar com falas significativas se nunca ninguém tinha ouvido falar nisso? Então, era muito desafiador para todos [...]. (P2, 2013, grifos nossos).

No começo a gente fez uma discussão em cima da educação tradicional e daí uma educação mais popular e muita gente se ofendeu porque o tradicional era o que eles faziam. Eu acho que a gente também fez uma coisa equivocada, porque o tradicional não é ruim, ele alfabetizou a mim, a você, a todos nós. Na verdade a gente entrou por um viés muito complicado, que se fosse hoje, por exemplo, teria que repensar como é que você entra nisso [...]. $A$ mudança, ela assusta, e a gente assustou muito no começo. (P5, 2012, grifos nossos).

$O$ tema gerador faz com que as pessoas reflitam muito mais, pensem mais, busquem, tem que procurar, tem que estudar, tem que pensar realmente o que tu quer trabalhar com a criança, a partir daquela dificuldade. Então, essa também foi uma situação que a gente teve que enfrentar, as pessoas não queriam, nem sempre queriam ler, estudar. Queriam sim é fazer mimos nas paredes, coisinhas aqui, coisinhas acolá, que fosse uma coisa bonita. Aí, [...] você ficar fazendo essas coisinhas sem ter que pensar, sem ter que ler, estudar, debater, é muito mais fácil do que você ter que buscar, procurar. (P1, 2012, grifos nossos).

$A$ resistência a ter que pensar sobre o que faz, a abrir o livro didático, que se lia de cabo a rabo, sem se perguntar por que, pra que, pra quem, o que, se tem que planejar em função do que, a resistência em se colocar em movimento, em ter que se abrir, você dá tua aula, mas a tua aula, ela não é uma coisa só tua, ela é coletiva. (P4, 2012, grifos nossos).

O estudo de Stuani (2010), que focou a formação continuada dos professores de Ciências Naturais vivenciada ao longo deste processo, também identificou pontos de 
resistência à proposta. Segundo a autora, a principal justificativa para essa postura esteve na falta de clareza dos docentes quanto à proposta, aspecto que pode ser depreendido deste depoimento:

E o que você constata é um grande número de educadores que têm um pedaço tão pequeno de poder e que nem é definido por ele, alguém definiu por ele, e ele reproduz aquilo, aquelas aulas, repassa aquilo como se fosse o verdadeiro conhecimento, como se aquilo fosse uma verdade absoluta, sem se quer se perguntar se dá pra fazer de outro jeito, se isso que eu estou trabalhando, estou trabalhando porque, pra que, para quem? $(P 4,2012)$.

Explicitando melhor a compreensão dos entrevistados quanto a essa resistência dos docentes à proposta, evidencia-se que o fato do professor precisar lidar com o tema gerador, partir da realidade do aluno e das suas falas significativas, representou um grande desafio, por vezes obstaculizando a participação na construção da proposta:

Os professores tinham dificuldade e diziam "eu não sei fazer", não era uma resistência, era uma resistência no sentido do não saber fazer "eu não sei trabalhar com a fala, eu não consigo enxergar ciência na fala, a matemática na fala, eu vou dar minhas quatro operações, os números inteiros, negativos e raiz, raiz quadrada, eu não sei trabalhar isso na fala, eu não sei trabalhar com os três momentos pedagógicos". Então o povo dizia abertamente que não sabia, eles diziam que não sabiam e da dificuldade que eles tinham [...]. Muitos também não sabiam lidar com as perguntas que vinham dos alunos, porque instigava os alunos a participar, perguntar. (P2, 2012, grifos nossos).

Outra coisa difícil foi o tema gerador. Não é fácil. Construir aquela rede toda era uma situação difícil, a rede temática que a gente construía era muito complicada e o grupo se ressentia disso, tinha dificuldade de fazer, porque não é pegar botar um item em baixo do outro e dizer "eu vou fazer isso". Tinha que olhar pro micro, pro macro [...]. Então a gente introduziu muitas situações diferenciadas, $e$ isso se tornou difícil pro professor fazer, na prática dele. A gente tinha uma equipe pequena, daí, pra andar por todos os lugares [...]. A que a gente queria ser sistemático na formação também. Foi uma situação difícil. (P5, 2012, grifos nossos).

Acho que faltou um pouco de interesse e conhecimento mesmo, conhecimento de um todo, porque de repente você não pode conhecer apenas a tua área, você tem que conhecer as propostas, 
diferentes propostas, você tem que saber o que você está trabalhando [...], que o aluno aprende, como é que cada ser humano consegue se inserir, digerir esse conhecimento, de que forma ele se apropria dele [...], porque primeiro tu tem que conhecer muito bem 0 aluno, tem que conhecer a realidade, porque se tu não conhecer a realidade, eu acho que faltou bastante preparação $e$ conhecimento, eu diria como um todo, teoria mesmo, teoria até das próprias áreas, [...]. (P6, 2013, grifos nossos).

Portanto, a construção do currículo foi afetada por essa dificuldade na compreensão do tema gerador e de seus desdobramentos no cotidiano da unidade escolar. Por outro lado, vale destacar que dúvidas e incertezas também podem ter se caracterizado como motivações ao estudo e à reflexão crítica:

Os professores diziam que o conteúdo do currículo, e o vestibular... Trabalhar com a fala não garante os conteúdos do currículo, porque eles tinham dificuldade em ver os conteúdos do currículo. (P2, 2012, grifos nossos).

A gente ouviu críticas o tempo todo, que os conteúdos não eram trabalhados, [...] ficavam sempre no senso comum, que não se avançou nesse sentido, como é que você vê essa relação, como é que dava esse salto de uma coisa pra outra? (P4, 2012, grifos nossos).

Os professores dizem como trabalhar com a fala, não vejo a minha disciplina, minha área na fala. Em que a área vai contribuir pra fala, pra que serve a rede temática, como trabalhar os três momentos pedagógicos em sala de aula, será que eu sei problematizar, o que eu estou fazendo é de fato a aplicação do conhecimento ou não, na organização do conhecimento o pessoal tinha mais o trânsito, a aplicação do conhecimento e a problematização o pessoal tinha bastante dificuldade em organizar. (P2, 2013, grifos nossos).

Entendemos, na oportunidade, que era pra trabalhar somente os problemas sociais, seria só a problematização e aí, o que aconteceu, deixamos pra trás aspectos fundamentais da matemática, do português $e$ de todas as disciplinas, [...] que embora elas se encaixassem lá no tema gerador, entendemos que a problematização era mais importante do que o trabalho dos conteúdos em si. Aí, cometemos o erro de achar que os conteúdos, a partir de então, não eram mais necessários de serem trabalhados, não havia mais necessidade de se trabalhar os conteúdos. A meu ver essa foi a parte mais delicada do processo, 
porque poucos se alfabetizaram neste período. (P7, 2013, grifos nossos).

Freire e Shor (2003) apontam que refletir sobre a prática exige do professor mergulhar no mundo das suas experiências e de seus sentimentos, percebendo, a partir de uma compreensão teórica, o que ocorre no mundo da objetividade. Essa postura exige compromisso, suplantando a compreensão de mera presença física do ser no mundo.

Em uma avaliação mais global do processo, levando em consideração o conjunto de ações na implementação dessa política educacional, alguns aspectos foram apontados como imprescindíveis à revisão, reflexão crítica e recriação:

A gente vinha com ideias diferentes e desmontando coisas que estavam na prática das pessoas, nós também éramos desajeitados na hora de desmontar porque, pra desmontar, é verdade, a gente tinha insegurança, então, a gente ia com uma forma meio dura naquilo que a gente acreditava $e$ isso fazia uma quebra que se hoje, eu tivesse experiência, e hoje eu tenho, ou se eu conhecesse um pouquinho mais, como eu acho que conheço hoje o que Paulo Freire diz, talvez eu tivesse sido mais cuidadosa em algumas coisas e tivesse construído mais [...], talvez a gente tivesse conquistado mais, porque algumas pessoas a gente acaba afastando, porque as pessoas fazem durante muito tempo aquilo, e aquilo pra elas se torna uma verdade e você vai lá e chuta uma verdade deles como se isso fosse uma coisa muito tranquila, é tranquilo pra ti, mas não é tranquilo pro sujeito que está naquela situação. (P5, 2002, grifos nossos).

A proposta foi sendo construída com o passar do tempo, de mês a mês, de semana a semana. Porém percebíamos que também não dominavam plenamente o que nos repassavam [...]. Adoecemos, choramos, porque percebemos que o que sabíamos e fazíamos não cabia mais e também não sabíamos e não sentíamos segurança em fazer o novo. Caímos no nada. Eu entendo que a proposta foi uma mudança muito brusca da educação quantitativa para a qualitativa, foi rápida demais. Compreendo que uma mudança tem que ser muito bem estruturada, trabalhada de forma gradativa, afinal, nada se dá aos saltos. Causou muito descontentamento nos professores [...], faltou segurança, coesão, aporte, estrutura pedagógica e física. (P6, 2013, grifos nossos).

Observa-se que o movimento reflexivo proporcionou uma avaliação dos fazeres pedagógicos no âmbito da gestão da política educacional, despertando para a necessidade de avaliação em todos os âmbitos, tendo em vista a ousadia de uma educação crítica que se 
constrói continuamente, mediante uma ação coletiva. $\mathrm{O}$ conflito parece ser a motivação para a continuidade desse trabalho sem fim que é a ressignificação da prática pedagógica. Borges (2000, p. 239), explicita a naturalidade com que tais sentimentos vêm à tona no processo de reflexão sobre a prática em movimento:

Quando um educador, comprometido politicamente com seus alunos, começa a
refletir criticamente sobre sua prática pedagógica, muitas inquietações e indagações
se apresentam. Acompanhando a racionalidade necessária ao pensamento reflexivo e
crítico, sentimentos diversos: medo, revolta, ousadia, rebeldia, tristeza e alegria,
compõem o ser, a pessoa do educador, que não se abre para que o conformismo e a
acomodação se instalem.

Sabemos que a formação continuada de professores tem sido descuidada no Brasil, contudo, conforme orienta Freire apud Borges (2000, p. 245), "Não vamos impor ideias, teorias ou métodos, mas vamos lutar, pacientemente impacientes, por uma educação como prática de liberdade. Nós acreditamos na liberdade. Queremos bem a ela."

Pensar criticamente sobre a própria prática pedagógica e ousar a mudança são desafios que demandam a predisposição para dialogar com as diferenças, para enfrentar e superar limites, tendo clareza acerca de onde queremos chegar.

\section{CONSIDERAÇÕES FINAIS}

O estudo possibilitou identificar e analisar aspectos do processo de formação continuada dos educadores realizado durante o movimento de reorientação curricular ocorrido no município de Chapecó (SC) no período entre 1997 e 2004.

O destaque foi para as condições objetivas de trabalho que oportunizaram a implementação da proposta, notadamente a disponibilidade de carga horária aos docentes e a oferta de assessoria permanente, a fim de orientar o processo. Com relação às ações formativas, os professores apontam a atenção constante às dificuldades enfrentadas no cotidiano escolar, tendo em vista a proposta em ação: a contínua reflexão sobre a própria prática pedagógica e a importância do trabalho coletivo e interdisciplinar. Dificuldades também foram apontadas, com maior ênfase a resistência dos docentes à mudança e as dificuldades na compreensão da proposta, com implicações na construção coletiva do currículo.

Vale destacar que projetos dessa natureza, que geram impacto na formação dos educadores, são de grande importância para a construção de uma educação de qualidade e 
inclusiva. Contudo, parece relevante que tais perspectivas possam impregnar também a formação inicial, promovendo uma maior aproximação desta com o cotidiano da escola, de modo que a formação continuada não seja um "retrabalho", buscando eternamente suplantar carências da formação inicial, e possa orientar-se em programas que primam pela profissionalização docente (IMBERNÓN, 2009).

Nesta direção, o Programa Institucional de Bolsas de Iniciação à Docência (PIBID) parece estar contribuindo, na medida em que objetiva inserir os licenciandos no cotidiano escolar, levando-os a participar das experiências pedagógicas em desenvolvimento e, assim, contribuir para a superação das dificuldades vivenciadas no processo ensino-aprendizagem e, desta forma, articular formação inicial e continuada.

\section{REFERÊNCIAS}

ALARCÃO, Isabel. Professores reflexivos em uma escola reflexiva. São Paulo: Cortez, 2003.

BARDIN, Laurence. Análise de conteúdo. Lisboa, Portugal: Edições 70, 2009.

BOGDAN, R.; BIKLEN, S. Investigação qualitativa em educação: uma introdução à teoria e aos métodos. Portugal: Porto Editora, 1994.

BORGES, Isabel Cristina Nache. Uma experiência de formação docente na gestão Paulo Freire. In: SAUL, A. M. Paulo Freire e a formação de educadores: múltiplos olhares. São Paulo: Articulação Universidade/Escola, 2000.

BRZEZINSKI, I.; GARRIDO, E. Análise dos trabalhos do GT Formação de Professores: o que revelam as pesquisas do período de 1992-1998. Revista Brasileira de Educação, Rio de Janeiro, ANPED: Campinas, Autores Associados, n. 18, p. 82-100, Set./Out./Nov./Dez. 2001. http://dx.doi.org/10.1590/S1413-24782001000300008

CONTRERAS, José. Autonomia de professores. São Paulo: Cortez, 2002.

DELIZOICOV, Demétrio. La Educación em Ciências y La Perspectiva de Paulo Freire. Alexandria - Revista de Educação em Ciências e Tecnologia, Florianópolis: UFSC, v. 1, n. 2, p. 37-62, jul. 2008. https://doi.org/10.5007//39371

FREIRE, Paulo. A educação na cidade. São Paulo: Cortez, 1999.

. Ação cultural para a liberdade e outros escritos. Rio de Janeiro: Paz e Terra, 1987.

. Extensão ou comunicação?. São Paulo: Paz e Terra, 2006.

Pedagogia da autonomia: saberes necessários à prática educativa. São Paulo: Paz e Terra, 2001. 
. Política e educação: ensaios. São Paulo: Cortez, 1997.

FREIRE, P.; SHOR, I. Medo e ousadia: o cotidiano do professor. Rio de Janeiro: Paz e Terra, 2003.

IMBERNÓN, Francisco. Formação docente e profissional: formar-se para a mudança e a incerteza. São Paulo: Cortez, 2009.

MAFRA, J. F.; QUERUBIM, V. R. Paulo Freire e a academia. Eccos Revista Científica, São Paulo: ANPUH, n. 26, p. 19-36, jul/dez. 2011. https://doi.org/10.5585/eccos

MINAYO, Maria Cecília de Souza (Org.). Pesquisa social: teoria, método e criatividade. Rio de Janeiro: Vozes, 2003.

SILVA, Antonio Fernando Gouvea. A construção do currículo na perspectiva popular e crítica das falas significativas às práticas contextualizadas. 2004. 539f. Tese (Doutorado em Educação) - Pontifícia Universidade Católica de São Paulo, São Paulo.

STUANI, Geovana Mulinari. A construção curricular popular crítica no ensino de Ciências Naturais e suas implicações na prática docente. 2010. 194f. Dissertação (Mestrado em Educação Científica e Tecnológica) - Universidade Federal de Santa Catarina, Florianópolis. 